\title{
Evaluation of Diuretic Activity of Aqueous Extract of Ripe Fruit Pulp of Tamarindus indica $L$. in Rats
}

\author{
Sammodavardhana Kaundinnyayana ${ }^{1}$, Satish Kumar Mahadevaiahchandraiah ${ }^{2}$, Alaya \\ Laxminarayana Udupa ${ }^{3}$
}

\begin{abstract}
${ }^{1}$ Department of Pharmacology, Nepalese Army Institute of Health Sciences, Kathmandu, Nepal. ${ }^{2}$ Novartis Pharmaceuticals, Hyderabad, India. ${ }^{3}$ Department of Pharmacology, Azeezia Institute of Medical Sciences and Research (AIMSR), Kerala, India.
\end{abstract}

\section{ABSTRACT}

Introduction: Diuresis is an important pharmacological property which is useful in many clinical conditions. There is a need of better diuretics with lesser adverse effects in comparison to currently available diuretics. The study aimed to evaluate the diuretic activity of aqueous extract of fruit pulp of Tamarindus indica L. in rats.Methods: The study was undertaken with aqueous extract of fruit pulp of Tamarindus indica in three doses: $300 \mathrm{mg} / \mathrm{kg}, 600 \mathrm{mg} / \mathrm{kg}$ and1200 mg/kg for its diuretic activity in comparison with standard (furosemide) and vehicle control (normal saline) in Wistar rats. Urine volume and electrolytes were measured after 24 hours of drug administration. Results: Aqueous extract of fruit pulp of Tamarindus indica at the dose of 1200 $\mathrm{mg} / \mathrm{kg}$ exhibited significant diuretic activity $(\mathrm{p}<0.05)$ without significant natriuretic effect. Magnesium excretion was also significantly increased in comparison to control group. Conclusion: Aqueous extract of fruit pulp of Tamarindus indica has significant diuretic activity in Wistar rats.
\end{abstract}

Keywords: aqueous extract; diuretic activity; metabolic cage; tamarindus indica

\section{INTRODUCTION}

Diuresis is an important pharmacological property, useful in many clinical conditions like hypertension, congestive cardiac failure, renal failure, nephrotic syndrome and many other situations where there is fluid overload or electrolyte imbalance. ${ }^{1}$ Although numerous diuretics belonging to different classes are available for clinical use, all of them have adverse effects, some of which may prove to be very serious and sometimes even fatal. ${ }^{1,2}$ In addition to this, there is possibility of emergence of resistance to many of the diuretics after prolonged use. ${ }^{2}$ For these reasons, there is considerable interest in search for an ideal diuretic which is free of the adverse effects seen with existing diuretics and remains efficacious without development of resistance.

The recent resurgence of plant remedies results from several factors like their effectiveness and lesser side effects compared

Correspondence: Sammodavardhana Kaundinnyayana, Dept of Pharmacology, Nepalese Army Institute of Health Sciences, Sano Bharyang, Kathmandu, Nepal. E-mail: sammodacharya@gmail.com, 
to modern medicines in most of the cases. This is evident by the increase in number of reports supporting the claim of efficacy of medicinal plants. ${ }^{3,4}$ Tamarindus indica L. is an evergreen tree which is cultivated worldwide and also partly naturalized in the tropics and subtropics. ${ }^{4}$ In traditional medicine, different parts of the plants viz. pulp of fruits, seeds, leaves, flowers and bark have been used for various indications. $^{5-9}$ Ethno-botanical uses of leaves and ripe fruit pulp of Tamarindus indica as diuretic have been reported. ${ }^{10,11}$ There is lack of systematic preclinical or clinical evaluation of diuretic activity of fruit pulp. Hence this study was carried out to obtain preclinical evidence for diuretic efficacy of the ripe fruit pulp of Tamarindus indica $\mathrm{L}$.

\section{METHODS}

The experiment was conducted as per CPCSEA guidelines after obtaining approval from the Institutional Animal Ethics Committee (IAEC).

\section{Materials}

- Aqueous extract of ripe fruit pulp of Tamarindus indica Linn.(AEFTI)

- Animals: Inbred albino rats of Wistar strain, of either sex, weighing 150-200 g.

- Drugs: Furosemide, (Lasix, $10 \mathrm{mg} / \mathrm{mL}$, Aventis Pharma Limited, India), Normal saline

- Metabolic cages (Nalgene, USA, Model 650-0100. Figure 1)

\section{Procedure}

Fresh ripe fruits of Tamarindus indica were procured from local market and verified by a botanist. A sample of fruits of T. indica was deposited in the department for future

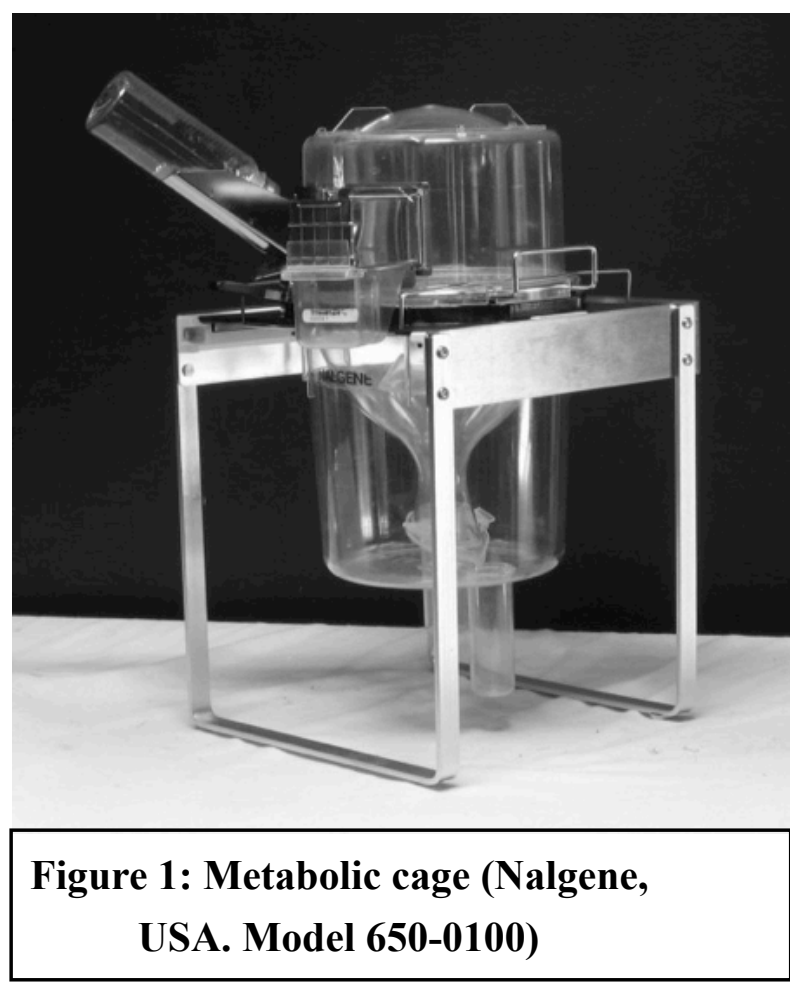

reference. Ripe dried pods of T.amarindus indica were peeled, deseeded, and air-dried in shade for ten days. Dried fruit pulp is a gummy substance easily miscible in water. Half a kilogram of the dried pulp was tied in a thin muslin cloth and soaked in 1 liter of distilled water for 60 minutes and then boiled for a duration of two hours. The residue tied in the cloth was discarded after lightly squeezing out the liquid part. The extract was concentrated over low flame for about one hour to a thick consistency and then kept in hot air oven for 48 hours at $50^{\circ} \mathrm{C}$. The yield was $24 \%$ of the pulp. It was then kept in a desiccator for daily use. Fresh solutions of the drug were prepared before experiments. Required quantity, according to the dose and body weight of animals, was dissolved in normal saline for oral administration.

Acute toxicity study of the extract was not done as it was reported previously with no 
Table 1: Effect of aqueous extract of fruit pulp of Tamarindus indica (AEFTI) on 24 hour urine volume, electrolytes and oxalate level in urine $(\operatorname{Mean} \pm \operatorname{SEM})(\mathrm{n}=6)$

\begin{tabular}{|c|c|c|c|c|c|c|c|}
\hline $\begin{array}{l}\text { Drug } \\
\text { Dose } \\
(\mathrm{mg} / \mathrm{kg})\end{array}$ & $\begin{array}{l}\text { Urine } \\
\text { volume } \\
\text { (ml) }\end{array}$ & $\begin{array}{l}\text { Sodium } \\
\text { (mmol/L) }\end{array}$ & $\begin{array}{l}\text { Potassium } \\
\text { (mmol/L) }\end{array}$ & $\begin{array}{l}\text { Chloride } \\
\text { (mmol/L) }\end{array}$ & $\begin{array}{l}\text { Magnesiu } \\
\mathrm{m} \\
(\mathrm{mg} / \mathrm{dL})\end{array}$ & $\begin{array}{l}\text { Calcium } \\
\text { (mg/dL) }\end{array}$ & $\begin{array}{l}\text { Oxalate } \\
\text { (mg/dL) }\end{array}$ \\
\hline
\end{tabular}

\section{Control}

$(0.9 \%$

$8.80 \pm 0.53$

$61.30 \pm 1.4$

$54.22 \pm 3.0$

$127.77 \pm 6 . \quad 3.72 \pm 2.06$

$7.85 \pm 1.42 \quad 44.40 \pm 4.6$

saline)

8

2

66

1

\begin{tabular}{|c|c|c|c|c|c|c|c|}
\hline $\begin{array}{l}\text { Standard } \\
\text { (Frusemid } \\
\text { e } \\
25 \mathrm{mg} / \mathrm{kg} \text { ) }\end{array}$ & $\begin{array}{l}16.57 \pm 0.3 \\
8^{\star}\end{array}$ & $\begin{array}{l}75.47 \pm 8.3 \\
0\end{array}$ & $\begin{array}{l}95.05 \pm 19 . \\
4\end{array}$ & $\begin{array}{l}184.00 \pm 1 \\
6.65\end{array}$ & no data & no data & $\begin{array}{l}54.47 \pm 5.7 \\
4\end{array}$ \\
\hline $\begin{array}{l}\text { AEFTI } \\
300 \mathrm{mg} / \\
\mathrm{kg}\end{array}$ & $\begin{array}{l}13.80 \pm 1.6 \\
8\end{array}$ & $\begin{array}{l}80.20 \pm 10 \\
68\end{array}$ & $\begin{array}{l}182 \pm 26.5 \\
7^{\star}\end{array}$ & $\begin{array}{l}154.97 \pm 2 \\
8.81\end{array}$ & $\begin{array}{l}40.60 \pm 10 \\
24^{\star}\end{array}$ & $8.57 \pm 0.75$ & $\begin{array}{l}61.05 \pm 1.0 \\
2\end{array}$ \\
\hline $\begin{array}{l}\text { AEFTI } \\
600 \mathrm{mg} / \\
\mathrm{kg}\end{array}$ & $\begin{array}{l}12.07 \pm 1.8 \\
3\end{array}$ & $\begin{array}{l}59.55 \pm 9.3 \\
2\end{array}$ & $\begin{array}{l}193.20 \pm 5 \\
5.79 *\end{array}$ & $\begin{array}{l}222.30 \pm 4 \\
4.88^{\star}\end{array}$ & $\begin{array}{l}56.70 \pm 13 . \\
12^{*}\end{array}$ & $6.50 \pm 0.28$ & $\begin{array}{l}76.97 \pm 0.8 \\
0 * *, \ddagger\end{array}$ \\
\hline $\begin{array}{l}\text { AEFTI } \\
1200 \mathrm{mg} / \\
\mathrm{kg}\end{array}$ & $\begin{array}{l}14.50 \pm 2.9 \\
5^{\star}\end{array}$ & $\begin{array}{l}80.72 \pm 11 \\
65\end{array}$ & $\begin{array}{l}139.42 \pm 3 \\
4.09\end{array}$ & $\begin{array}{l}207.32 \pm 3 \\
2.39\end{array}$ & $\begin{array}{l}60.50 \pm 16 \\
74^{\star}\end{array}$ & $\begin{array}{l}12.92 \pm 5.2 \\
6\end{array}$ & $\begin{array}{l}74.10 \pm 3.4 \\
2^{* *}, \neq\end{array}$ \\
\hline
\end{tabular}

evidence of acute toxicity up to $8 \mathrm{~g} / \mathrm{kg}$ of the extract. $^{12}$

The method for evaluation of diuretic activity described by Kau et al. with modifications was used. ${ }^{13}$

Inbred albino rats of Wistar strain of either sex weighing 150-200 g were used. They were housed in standard environmental conditions of temperature $\left(25 \pm 2^{\circ} \mathrm{C}\right)$, relative humidity $(50-55 \%)$ and approximately 12 hours natural light per day of in the institutional animal house. They were fed standard pellet diet (Hindustan Lever rat pellets) and water $a d$ libitum.

Thirty animals were divided into five groups: control, standard drug and three treatment groups $(n=6)$. Furosemide solution for injection (Lasix, $10 \mathrm{mg} / \mathrm{mL}$, Aventis Pharma Limited, India) was used in a dose of $25 \mathrm{mg} /$ $\mathrm{kg}$ orally as the standard drug. Three doses of aqueous extract of ripe fruit pulp of Tamarindus indica (AEFTI): $300 \mathrm{mg} / \mathrm{kg}, 600$ $\mathrm{mg} / \mathrm{kg}$ and $1200 \mathrm{mg} / \mathrm{kg}$ were tested in the treatment groups for diuretic activity. After overnight fasting, animals were orally administered normal saline, standard drug (furosemide) or different doses of test drug, all reconstituted to same volume. Urine output was collected for 24 hours housing each animal in a separate metabolic cage (Nalgene, USA, Model no 650-0100, Figure 1), kept in standard environmental conditions of institutional animal house. The animals had free access to water but not to food. The volume of urine was measured at 24 hours of 
drug administration. Urine samples were taken separately for each animal and were quantitatively analyzed for sodium, potassium, chloride, calcium, magnesium and oxalate levels in the biochemistry laboratory. The procedure was repeated thrice after a wash out period of 2 weeks each and mean for each animal was taken for statistical evaluation.

Statistical evaluation was done by using ANOVA in SPSS version 10. Scheffe test was used for test of significance. $\mathrm{P}$ value $<0.05$ was taken as significant and $<0.001$ was taken as highly significant.

\section{RESULTS}

Results are summarized in Table 1. Aqueous extract of ripe fruit pulp of Tamarindus indica (AEFTI) revealed significant $(\mathrm{p}<0.05)$ increase in the volume of urine in the dose of $1200 \mathrm{mg} / \mathrm{kg}$. There was no significant increase in the excretion of sodium, but excretion of potassium and chloride was significantly increased, although there was no linear relation with dose of the extract. There was significant increase in urinary magnesium level in all doses compared to control group. There was highly significant increase in urinary oxalate excretion $(p<0.001)$ in the rats receiving all doses of AEFTI in comparison to control group and in the groups receiving 600 $\mathrm{mg} / \mathrm{kg}$ and $1200 \mathrm{mg} / \mathrm{kg}$ doses in comparison to standard group.

\section{DISCUSSION}

The fruit pulp of Tamarindus indica has a strongly acid taste and contains chiefly tartaric acid (about 10\%), acid potassium tartrate (about 8\%), and invert sugar (from 25 to $40 \%)$. The total acidity varies from 11 to $16 \%$. 14 It contains around 400 compounds and elements with diverse biochemical properties and pharmacological activities including antiinflammatory, analgesic, antipyretic, antidiabetic and diuretic properties. ${ }^{6,7}$

Although the aqueous extract of fruit pulp of Tamarindus indica showed significant diuretic activity only in the highest dose $(1200 \mathrm{mg} / \mathrm{kg})$ used in the study, diuretic effect was seen in all the three doses used. Dose response relationship was not linear within the dose range which may be due to the small sample size and variability in the normal renal physiology of rats. Constituents of fruit pulp of Tamarindus indica already characterized to have diuretic activity are magnesium, ascorbic acid, calcium, potassium, and terpinen-4-ol which may be responsible for diuretic activity of the extract although other compounds not yet characterized may also be responsible. ${ }^{15}$ Urine analysis also showed significant increase in magnesium levels in the treated rats with all three doses in comparison to the control group. Although this study shows significant increase in urinary oxalate level in rats treated with the extract, tamarind ingestion has been shown to decrease the oxalic acid level and reduced lithogenic property of urine mainly due to tartaric acid content in some preclinical and clinical studies. ${ }^{16-19}$ Species difference in renal physiology may explain the apparent contradiction in oxalate excretion in human and rats with intake of fruit pulp of Tamarindus indica.

\section{CONCLUSION}

This study supports the traditional use of fruit pulp of Tamarindus indica as diuretic when significant sodium overload is not present, 
although larger scale preclinical and clinical studies are required for confirmation of clinical efficacy and safety. This traditional herbal extract may be further analyzed for the diuretic constituents for development of diuretic agents with better efficacy and tolerability. It is likely that the plant products may prove to be better tolerated diuretics in comparison to the existing ones. Besides having diuretic property, preventive effect on urolithiasis as shown by previous studies could be an advantage.

\section{ACKNOWLEDGEMENTS:}

Department of Botany MGM College, Udupi and Department of Biochemistry KMC Manipal for technical support and KMC trust for financial support.

\section{REFERENCES}

1. Reilly RF, Jackson EK. Regulation of renal function and vascular volume. In: Brunton LL, editor. Goodman and Gillman's the Pharmacological basis of therapeutics. 12th ed. NewYork: McGrawHill; c2011. p671-719.

2. Sam R, Pearce D, Ives HE. Diuretic agents. In: Katzung BG, editor. Basic and Clinical Pharmacology. 13th ed. NewYork: McGrawHill; c2015. p249-69.

3. Prasad KVSRG, Sujatha D, Bharathi K. Herbal Drugs in Urolithiasis - A Review. Pharmacognosy Reviews 1(1), 2007:175-9. http://www.phcogrev.com/article.asp? issn $=0973-7847$; year $=2007$; volume $=1$;issu $\mathrm{e}=1 ;$ spage $=175$; epage $=179 ;$ aulast $=$ Prasad; $\mathrm{t}$ ype $=2$

4. Silambarasan R, Ayyanar M. An ethnobotanical study of medicinal plants in
Palamalai region of Eastern Ghats, India. Journal of Ethnopharmacology 2015; 172: 162-178. Available at: http://dx.doi.org/ 10.1016/j.jep.2015.05.046

5. Mansfeld's World Database of Agricultural and Horticultural Crops [Online database] 2001.http://mansfeld.ipk-gatersleben.de/ apexfp=185:46:4717384216182::NO::mod ule,mf_use,source,akzanz,rehm,akzname,ta xid:mf,,botnam,0,,Tamarindus\%20indica, 17761 (Acsessed on June 20, 2015)

6. Kuru P. Tamarindus indica and its health related effects. Asian Pac J Trop Biomed 2014; 4(9): 676-81. DOI:10.12980/APJTB. 4.2014APJTB-2014-0173

7. Meher B, Dash DK, Roy A. A review on phytochemistry, pharmacology and traditional uses of Tamarindus indica $L$. World Journal of Pharmacy and Pharmaceutical Sciences 2014; 3(10): 229-40. http://www.wjpps.com/download/ article/1412070479.pdf

8. Lanhers MC, Fleurentin J and Guillemni F. Tamarindus indica Linn. Ethnopharmacologia 1996; 18: 42-57.

9. Havinga RM, Hartl A, Putcher J, Preshler $\mathrm{S}$, Buchman C, Vogle CR. Tamarindus indica L. Patterns of use in traditional African Medicine. J Ethnopharmacol 2010; 127(3): 573-88. http://10.1016/j.jep. 2009.11.028

10. United States Department of Agriculture (USDA), Agriculture Research Service (ARS). Germplasm Resources Information Network. Dr. Duke's Phytochemical and Ethnobotanical Databases. [Online Database] Updated 25 ${ }^{\text {th }}$ March 2010. http:// 
sun.ars-grin.gov:8080/npgspub/xsql/duke/ pl_act.xsql?taxon=992

11. De Caluwe E, Halamova K, Van Damme P. Tamarindus indica L. - A review of traditional uses, phytochemistry and pharmacology. Afrika Focus 2010; 23(1): 53-83. http://www.gap.ugent.be/ africafocus/pdf/vol23 1 tamarindus.pdf

12. Udupa AL, Rathnakar UP, Udupa S. Antiinflammatory, anti-pyretic and analgesic effects of Tamarindus indica. Indian Drugs; 44(6): 466-70.

13. Kau ST, Keddie JR, Andrews D. A method for screening diuretic agents in the rat. $\mathrm{J}$ Pharmacol Meth 1984; 11:67-75

14. Pharmaceutical Society of Great Britain. British Pharmaceutical codex 1911. http:// www.henriettes-herb.com/eclectic/bpc1911/ tamarindus.html

15. United States Department of Agriculture (USDA), Agriculture Research Service (ARS). Germplasm Resources Information Network. Dr. Duke's Phytochemical and Ethnobotanical Databases. [Online Database] Updated 25th March 2010. http://sun.ars-grin.gov:8080/npgspub/xsql/ $\mathrm{d} \mathrm{u} \mathrm{k}$ e / p 1 _ a c t 2 . x s q 1 ? taxon $=992 \&$ activity $=$ Diuretic

16. Joseph KC, Parekh BB, Joshi MJ. Inhibition of growth of urinary type calcium hydrogen phosphate dihydrate crystals by tartaric acid and tamarind. Current Science 88(8); 2005: 1232-38. http://www.currentscience.ac.in/ $\begin{array}{lllllllllll}\mathrm{D} & \mathrm{o} & \mathrm{w} & \mathrm{n} & 1 & \mathrm{o} & \mathrm{a} & \mathrm{d} & \mathrm{s} & /\end{array}$ article_id_088_08_1232_1238_0.pdf
17. Anasuya A, Sasikala M. Tartaric acid inhibits urinary stone formation in rats. Nutrition Research 1989; 9(5): $575-80 . h t t p: / / d x$.doi.org/10.1016/ S0271-5317(89)80182-4

18. Anasuya A, Sasikala M. Tamarind ingestion and lithogenic properties of urine in men. Nutrition Research 1990; 10: 110917 http://dx.doi.org/10.1016/ S0271-5317(05)80333-1

19. Rathore P, Pendse AK, Hada S, Sharma K, Singh PP. Effectiveness of tamarind (Tamarindus indica) therapy ( $3 \mathrm{gm}$ and 10 gm) on calcium oxalate and calcium phosphate crystallization using three different methods. Indian Journal of Clinical Biochemistry 1993; 8(2): 136-43. 